\title{
Article \\ Physiological Influence of Stalk Rot on Maize Lodging after Physiological Maturity
}

\author{
Jun Xue, Shang Gao, Liangyu Hou, Lulu Li, Bo Ming $\mathbb{1}^{0}$, Ruizhi Xie, Keru Wang, Peng Hou and Shaokun Li *®] \\ Institute of Crop Sciences, Chinese Academy of Agricultural Sciences/Key Laboratory of Crop Physiology and \\ Ecology, Ministry of Agriculture and Rural Affairs, Beijing 100081, China; xuejun5519@126.com (J.X.); \\ g382824817@126.com (S.G.); houliangyu@hotmail.com (L.H.); lilulu19910818@163.com (L.L.); \\ mingbo@caas.cn (B.M.); xieruizhi@caas.cn (R.X.); wangkeru@caas.cn (K.W.); houpeng@caas.cn (P.H.) \\ * Correspondence: lishaokun@caas.cn; Tel.: +86-10-82108891
}

Citation: Xue, J.; Gao, S.; Hou, L.; Li, L.; Ming, B.; Xie, R.; Wang, K.; Hou, P.; Li, S. Physiological Influence of Stalk Rot on Maize Lodging after Physiological Maturity. Agronomy 2021, 11, 2271. https://doi.org/ 10.3390 /agronomy11112271

Academic Editor: Diego Rubiales

Received: 1 October 2021

Accepted: 7 November 2021

Published: 10 November 2021

Publisher's Note: MDPI stays neutral with regard to jurisdictional claims in published maps and institutional affiliations.

Copyright: (c) 2021 by the authors. Licensee MDPI, Basel, Switzerland. This article is an open access article distributed under the terms and conditions of the Creative Commons Attribution (CC BY) license (https:// creativecommons.org/licenses/by/ $4.0 /)$.

\begin{abstract}
The stalk lodging caused by stalk rot after physiological maturity (PM) is a major factor restricting further development of mechanical grain harvesting in China. The physiological mechanism of stalk rot on maize stalk lodging after PM is not clear. This study, based on investigating stalk rot under natural field conditions, demonstrated the relation between stalk rot caused by Fusarium spp. and lodging of 35 maize cultivars after PM. In addition, three widely-planted maize cultivars were inoculated with Fusarium spp. at PM to analyze the pathogen of stalk rot causing lodging, by measuring the infection process, carbohydrate contents, and mechanical strength of stalks. Stalk lodging increased by $0.11-0.32 \%$ for each $1 \%$ incidence of stalk rot. The stalk rot pathogen infected stalks from the pith to the rind. At the level of longitudinal section, the stalk rot pathogen spread from the inoculation internode upwardly and downwardly. These infections gradually increased with the days after PM. Inoculated plants had decreased soluble sugar content; however, cellulose and lignin contained in the inoculated plants were both higher than that in the non-inoculated treatment. Crushing strength was significantly and positively correlated with percentage of soluble sugar. This indicated that the reduction of soluble sugar content during the natural senescence of maize stalk after PM was an important factor for the decrease of stalk strength and the increase of stalk lodging. The occurrence of stalk rot accelerated the decomposition of soluble sugar, which accelerated the decrease of stalk strength and greatly increased risk of stalk lodging.
\end{abstract}

Keywords: maize; mechanical grain harvesting; lodging resistance; stalk rot; crushing strength

\section{Introduction}

Mechanical grain harvesting has become an essential role of maize (Zea mays) production in China [1]. When kernel moisture content is higher than $19.9 \%$, kernel breakage rate increased with the increase of kernel moisture content [2]. However, currently, the main maize cultivars planted in China always have a longer growth period with a slower dehydration rate of the kernel, such that kernel moisture content at physiological maturity is $32 \%$ for summer maize and $34 \%$ for spring maize [3]. The kernel moisture content reduces with the extension of the plant standing duration in the field [4,5], while there is an increased risk of lodging during grain dehydration in the field after PM [6,7]. Stalk lodging not only brings about grain loss, increases harvesting costs, but also reduces grain quality. Nevertheless, high stalk lodging-resistance after PM can make maize plants stand in the field for a longer time, which is conducive to mechanical grain harvesting of maize under a condition of lower kernel moisture content.

Stalk lodging is affected by plant morphology, carbohydrate content and mechanical strength of maize stalk [8]. After the PM of maize, plant and ear heights both hardly change, and the center of gravity height goes down due to leaves' senescence, internode breakage, and water loss in the upper part of the plant. In addition, the abscission of leaves reduces the wind resistance, to which the plant is subjected. The above morphological 
changes testify to improving the stalk lodging resistance after PM of maize. However, due to senescence, the degradation of carbohydrates and moisture loss cause the stalk's mechanical strength to decrease [7], which increases the risk of stalk lodging after PM.

After the PM of maize, stalk rot also increases the risk of lodging [9]. As one of the most destructive diseases during maize-growing throughout the world, stalk rot caused by Fusarium spp. can cause damage to the vascular bundles and may affect the absorption and translocation of water and nutrients, thereby reducing photosynthesis and grain development and resulting in premature plant death $[10,11]$. For each $1 \%$ increase in the incidence of stalk rot, the kernel loss rate single ear increases by $0.485 \%$, and the loss rate of 1000-kernel weight increases by $0.304 \%$ [12]. In China, the incidence rate of stalk rot in the field is 5-30\% [13], mainly caused by Fusarium graminearum and Pythium inflatum [14]. Further, stalk rot may also lower the quality of grain due to mildew.

Stalk rot is identified by the disintegration of pith tissue at or near base of the stalk and is associated with the senescence of stalk pith cells $[15,16]$. Furthermore, fungal hyphae from stalk rot pathogens block the vascular bundles and damage the transportation of water, nutrients, and soluble carbohydrates from photosynthesis [17], consequently accelerating stalk senescence. Therefore, a co-occurrence of the senescence of maize stalk and the infection of stalk rot provokes the decline in stalk quality.

The coverage of summer maize in the Huang-Huai-Hai area of China accounts for more than 10 million ha each year. Under a wheat-maize double cropping system, conservation tillage and crop residue management may lead to the increase of maize stalk rot in this area [18], in which the main pathogens of maize stalk rot are F. verticillioides, F. graminearum species complex (F. graminearum sensu stricto, F. meridionale, F. boothii, and F. asiaticum), Pythiumaristosporum and F. proliferatum [18-20].

In this study, the relationship between stalk rot and lodging was analyzed by investigating the stalk rot of 35 maize cultivars and their lodging after PM under natural field conditions. In addition, three widely planted maize cultivars were inoculated with Pythium aristosporum at PM to analyze how the stalk rot pathogen affects lodging by measuring the infection process, carbohydrate contents, and mechanical strength of the stalk. Theoretically, these results may provide a foundation for the breeding and cultivation of lodging-resistant maize cultivars that their plants can remain standing in the field after PM for better kernel dehydration.

\section{Materials and Methods}

\subsection{Experimental Site}

Two field experiments were conducted at the Xinxiang Experimental Station, Chinese Academy of Agricultural Sciences, Xinxiang, Henan Province, China $\left(35^{\circ} 18^{\prime} \mathrm{N}, 113^{\circ} 54^{\prime} \mathrm{E}\right)$ during maize growing seasons from 2017 to 2018. The soil was a clay loam that is classified as a Calcareous Fluvisol according the FAO-UNESCO classification system. The soil at a depth of 0-20 cm had the following characteristics: $18.9 \mathrm{~g} \mathrm{~kg}^{-1}$ organic matter, $78.5 \mathrm{mg} \mathrm{kg}^{-1}$ available nitrogen, $21.4 \mathrm{mg} \mathrm{kg}^{-1}$ available phosphorus, $162.0 \mathrm{mg} \mathrm{kg}^{-1}$ available potassium, and a $\mathrm{pH}$ of 8.8. The amount of precipitation and air temperature were measured by a weather station at the experimental site. The weather conditions of each month during the experiment are shown in Figure 1.

\subsection{Field Experiments}

Experiment 1 was designed to explore the relationship between stalk rot and stalk lodging. To ensure a wide range of genotype sources, 28 maize cultivars were planted in 2017, and 10 maize cultivars were planted in 2018 (Table 1), thereinto, such three cultivars as Zeyu 8911, Dika 517, and Dika 653 were both planted in 2017 and 2018. The planting density was $6.75 \times 10^{4}$ plants ha $^{-1}$ in 2017 and the plant density was $7.5 \times 10^{4}$ plants ha $^{-1}$ in 2018 in order to achieve higher grain yield. 

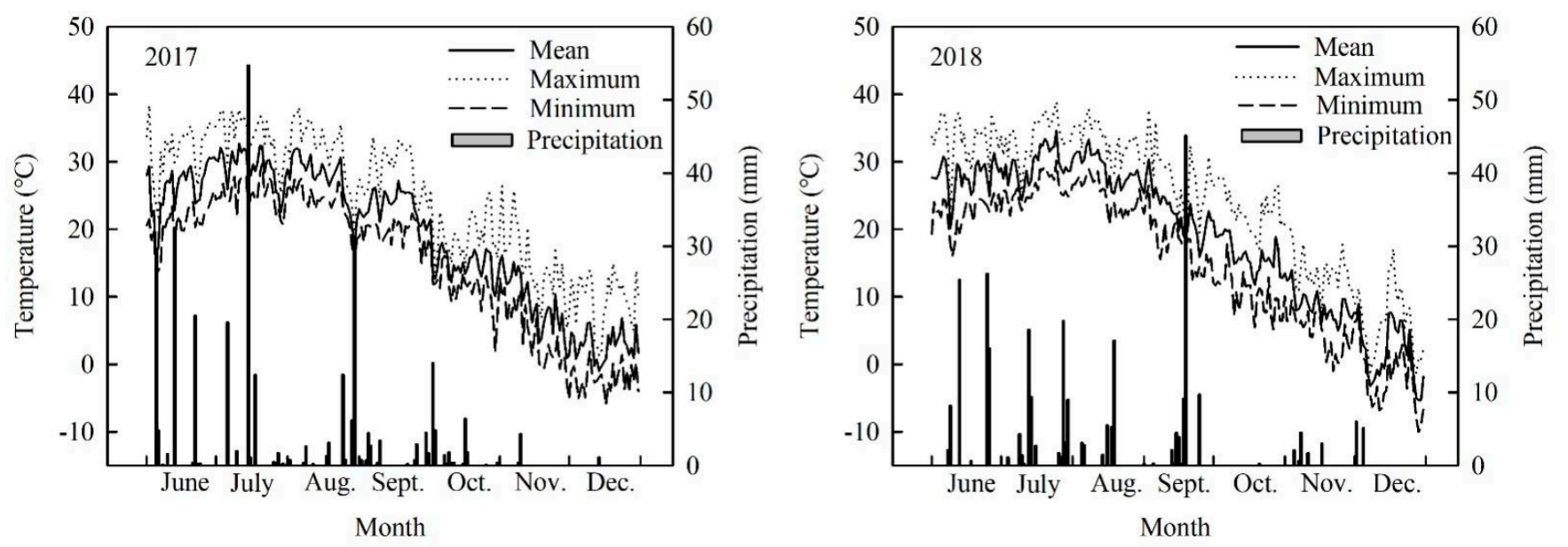

Figure 1. Temperature and precipitation during the growing seasons in 2017 and 2018.

Table 1. Experimental maize cultivars planted in 2017 and 2018.

\begin{tabular}{|c|c|c|}
\hline Year & Number of Cultivars & Cultivar Names \\
\hline 2017 & 28 & $\begin{array}{l}\text { Liaodan 586, Liaodan 585, Liaodan 575, MC 670, } \\
\text { Hengyu 898, Yuyu 30, Yufeng 303, Lianchuang 808, } \\
\text { Lianchuang 825, Lidan 295, LA 505, Beidou 309, Yudan } \\
\text { 9953, Xindan 58, Xindan 65, Xindan 68, Nonghua 5, } \\
\text { Nonghua 816, Dika 517, Dika 653, Shaandan 636, } \\
\text { Shaandan 650, Zeyu 501, Zeyu 8911, Jidan 66, Dongdan } \\
\text { 913, Jintong 152, Zhongkeyu } 505\end{array}$ \\
\hline 2018 & 10 & $\begin{array}{c}\text { Fengken 139, Hetian 1, Jingnongke 728, Dika 517, Dika } \\
\text { 653, Yudan 132, Xianyu 335, Zeyu 8911, Zhengdan 958, } \\
\text { Zhongdan } 909\end{array}$ \\
\hline
\end{tabular}

Experiment 2 was designed to explore how the stalk rot pathogen affects maize stalk lodging resistance after PM. Under natural conditions, the infection was launched prior to PM; however, the obvious symptoms of stalk rot rise rapidly after PM [21]. In addition, the infection of stalk inoculation treatment was faster than that under natural condition. Therefore, the $P$. aristosporum was inoculated into the stalk of three widely-planted maize cultivars (Zhengdan 958, Dika 517 and Jingnongke 728) at PM. The planting density was $7.5 \times 10^{4}$ plants ha ${ }^{-1}$ in 2017 and 2018. In China, Zhengdan 958 is the most widely planted cultivar of maize while Dika 517 and Jingnongke 728 have been developed to facilitate mechanical grain harvesting and close-planting of maize. These three cultivars were accredited in 2000, 2012, and 2014, respectively. The P. aristosporum was inoculated on Potato Dextrose Agar plate medium (200 g potato, 20 g glucose, $20 \mathrm{~g}$ agar, $1000 \mathrm{~mL}$ water) and cultured for 7 days till the hyphae took over the entire plate. Then, the agar and $P$. aristosporum were mixed with a concentration of $2.0 \times 10^{6} \mathrm{~mL}^{-1}$ for inoculation. Before inoculation, a drill with a diameter of $3 \mathrm{~mm}$ was used for opening a hole in the middle of the third basal internode above soil at PM, into which $0.5 \mathrm{~mL}$ of the mixture was injected. Then, petroleum jelly was smeared on the hole to prevent rainwater from flowing into the hole. More than 150 plants of each cultivar were inoculated in this way, and other healthy maize plants of each cultivar were plotted and served as controls.

In both years, each plot contained 10 rows with $25 \mathrm{~m}$ as length and $60 \mathrm{~cm}$ as space. All cultivars were arranged in complete randomized blocks, and the treatments for each cultivar were repeated three times. The sowing was done on 18 June 2017 and 13 June 2018, respectively. A controlled release fertilizer was applied during sowing, consisting of $156 \mathrm{~kg}$ $\mathrm{N} \mathrm{ha}^{-1}, 72 \mathrm{~kg} \mathrm{P}_{2} \mathrm{O}_{2} \mathrm{ha}^{-1}$, and $60 \mathrm{~kg} \mathrm{~K}_{2} \mathrm{O} \mathrm{ha}^{-1}$. Irrigation was performed when the winds were calm, based on the precipitation and in accordance with the water requirements of 
high-yield maize. At the eight-leaf stage, an insecticide, Ruining (2.5\% Beta-cyfluthrin, made by Nuopuxin, China), was sprayed to control the corn borers, and weeds were periodically removed artificially.

\subsection{Sampling and Measurements}

(1) Natural stalk rot and lodging percentage

The common harvest time of mechanical ear harvesting in Huang-Huai-Hai area was ranged from 1 October to 15 October. In order to reduce the kernel moisture content, in experiment 1 , the natural stalk rot and stalk lodging were investigated at four harvest times. In 2017, harvest dates were 27 October, 10 November, 25 November, and 6 December, respectively. In 2018, the harvest dates were 29 October, 12 November, 27 November, and 13 December, respectively.

Stalk rot was observed in a $24 \mathrm{~m}^{2}$ subplot $(10 \mathrm{~m} \times 4$ rows $)$ in the middle of each plot by squeezing stalks between the first and second aboveground nodes [22], and stalks were longitudinally split to inspect pith's discoloration of internodes, which was visible by darkening and pith deterioration [4]. The percentage of stalk rot was calculated by dividing the number of stalk rot plants by the total number of plants in the $10 \mathrm{~m}$ segments of the four test rows.

The number of stalk-lodged plants in each plot was recorded when the percentage of stalk rot was investigated. Plants were considered stalk-lodged when they were broken at or below the ear-bearing node [23]. The stalk lodging percentage was calculated by dividing number of stalk-lodged plants by total number of plants in $10 \mathrm{~m}$ segments of four test rows.

(2) Internode crushing strength of the inoculated stalks

In experiment 2, five maize plants were randomly selected from the inoculated and none-inoculated treatments, respectively. The crushing strength (CS), as the minimum force required to crush the stalk rind, was determined by means of a stalk strength tester (YYD-1, Zhejiang Top Instrument Co., Ltd., Hangzhou, China), which has been described by Xue et al. [24], comprised of a supporting structure, a force gauge with a digital display screen, and a test probe. The CS was measured with a cylindrical probe $\left(1-\mathrm{cm}^{2} \mathrm{cross}^{-}\right.$ sectional area), which was applied vertically to the internode at a slow uniform speed for breaking the rind. All of these measurements were taken at the middle of each internode, located at the widest side (about $15 \mathrm{~cm}$ above the soil line).

(3) Infection index of inoculated stalks

After measuring the crushing strength of the internode, the stalk was longitudinally split to inspect the pith for discoloration, and then the length of discoloration of the second $\left(l_{2}\right)$, third $\left(l_{3}\right)$, fourth $\left(l_{4}\right)$, and fifth $\left(l_{5}\right)$ internodes was measured with a ruler. The total length of the second $\left(L_{2}\right)$, third $\left(L_{3}\right)$, fourth $\left(L_{4}\right)$, and fifth $\left(L_{5}\right)$ internodes was also recorded (Figure 2). The internode infection index was calculated according to the following formula:

$$
\text { Infection index }=\frac{l 2}{L 2}+\frac{l 3}{L 3}+\frac{l 4}{L 4}+\frac{l 5}{L 5}
$$

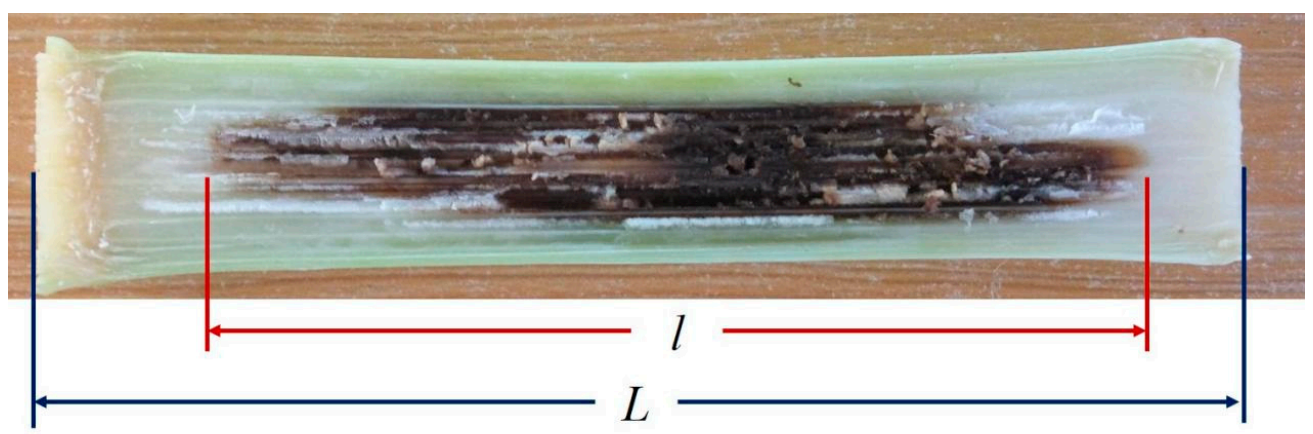

Figure 2. Schematic diagram for measuring infection index. 
(4) Carbohydrate contents of the inoculated internode

The third internode was immediately excised from the stalk of each plant after measuring infection index and deactivated in paper bags at $105^{\circ} \mathrm{C}$ for $30 \mathrm{~min}$, then dried to a constant weight at $80^{\circ} \mathrm{C}$. The entire internode was passed through a $1 \mathrm{~mm}$ screen for chemical analysis. The soluble sugar was measured as described by Yoshida et al. [25] and $\mathrm{Li}$ [26], with the addition of enthrone reagent; briefly, the samples were extracted in $80 \%$ ethanol $(v / v)$ to analyze the soluble sugar. The absorbance was measured at 620 $\mathrm{nm}$ by using a spectrophotometer (V-1800BPC, Shanghai MAPADA Instrument Co., Ltd., Shanghai, China). The percentages of neutral detergent fiber (NDF), acid detergent fiber (ADF), and acid detergent lignin (ADL) were measured by using a fiber system (A200 i, ANKOM, Macedon, NY, USA) as described by Van Soest et al. [27] and Zhou et al. [28]. The ash content was measured gravimetrically after igniting the dried residue in a muffle furnace, the weight of ash was recorded. The lignin content was calculated as the difference between ADL and the ash, the hemicellulose content was calculated as the difference between NDF and ADF, and the cellulose content was calculated as the difference between $\mathrm{ADF}$ and ADL. Carbohydrate composition analysis was performed in triplicate.

(5) Anatomical structure of the inoculated internode

Three additional maize plants were randomly selected from each plot. The third internode was excised from each plant and preserved in a mixture of formalin, acetic acid, and alcohol (FAA). Cross-sections that were approximately $20 \mu \mathrm{m}$ thick were cut from the middle of selected internodes artificially. The sections were stained with saffron, and the anatomical structure of the maize tissues was visualized under a light microscopy system (ML 10, Guangzhou Micro-shot Technology Co., Ltd., Guangzhou, China).

\subsection{Statistical Analysis}

Statistical analysis was performed with Predictive Analytics Software (PASW) version 18.0 (IBM SPSS, Somers, NY, USA). Data of each sampling date were analyzed separately. The means of natural stalk rot and lodging rate were tested with the least significant difference test at the level of $p<0.05$ (LSD 0.05) according to different harvest dates. In each year, analysis of variance was conducted with harvest dates, maize cultivars, and their interactions considered fixed effects, and replication and interactions with replications considered random effects. The maize cultivars within replications were the main-plot error term. Linear regression between natural stalk rot and lodging rate was conducted, and Pearson correlations were calculated to identify the relationships between carbohydrate percentage and CS.

\section{Results}

\subsection{Natural Stalk Rot Percentage}

The percentage of natural stalk rot gradually increased as cumulatively over time (Figure 3). In 2017, the average of stalk rot of 28 maize cultivars was $7.1 \%, 16.6 \%, 40.3 \%$, and $65.8 \%$ for the four harvest dates, respectively. In 2018, the average incidence rate of stalk rot of the 10 maize cultivars was $18.0 \%, 22.0 \%, 28.8 \%$, and $74.1 \%$ for the four harvest dates, respectively. Analysis of variance indicated that the natural incidence of stalk rot was significantly influenced by cultivar, harvest date, and their interactive effects. For the same cultivars, the increase rate of stalk rot percentage was higher in 2017 than that in 2018.

\subsection{Natural Stalk Lodging Rate}

The natural stalk lodging rate gradually increased with the delaying of harvest date after PM (Figure 4). In 2017, the average stalk lodging rate of 28 maize cultivars was $0.8 \%, 1.2 \%, 6.9 \%$, and $11.6 \%$ for the four harvest dates, respectively. In 2018 , the average stalk lodging rate of the 10 maize cultivars was $3.0 \%, 5.4 \%, 8.1 \%$, and $12.5 \%$ for the four harvest dates, respectively. Additionally, analysis of variance indicated that the natural stalk lodging rate was significantly influenced by cultivar, harvest date, and their interactive effects. 


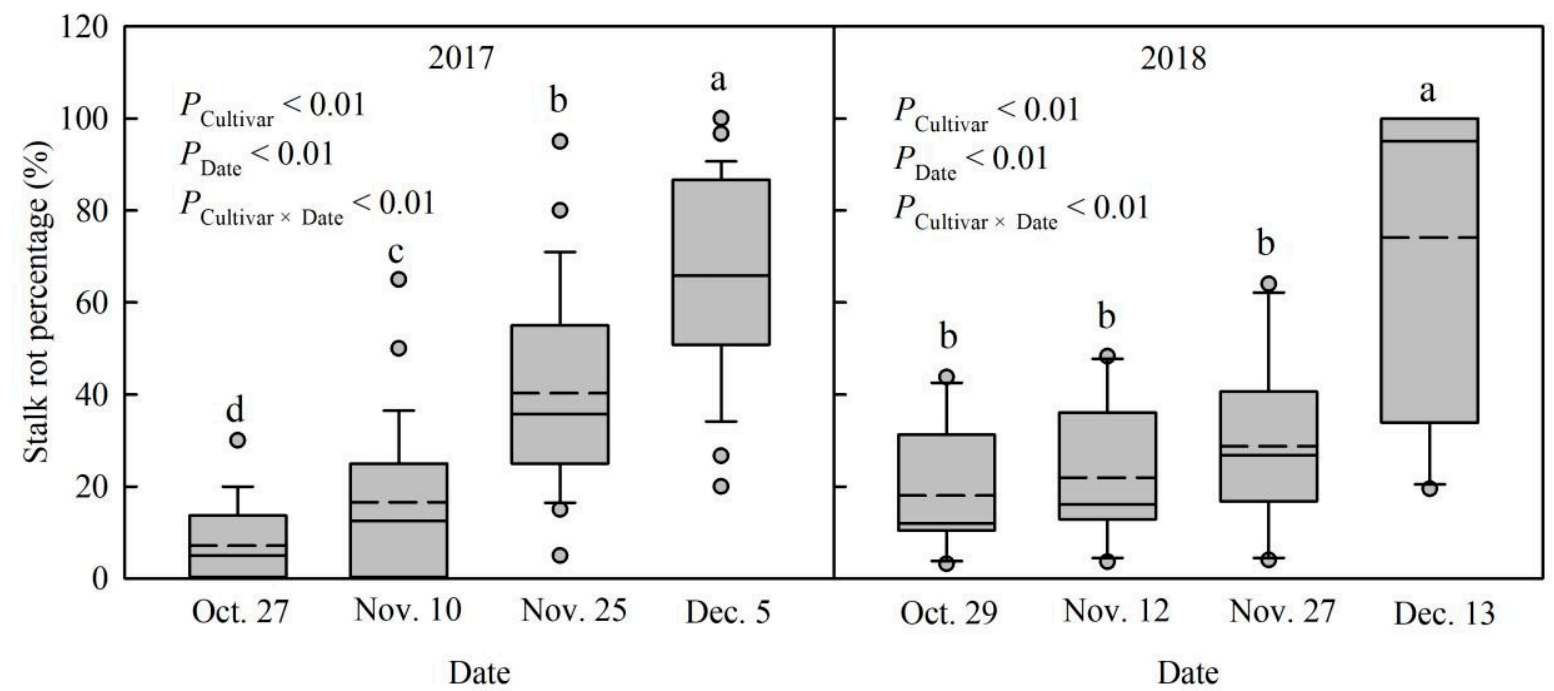

Figure 3. Stalk rot's natural incidence of different maize cultivars after physiological maturity. The main box designates an IQR containing 50\% samples in a Box-whisker Plot. The two sidelines indicate the reasonable sample border in Tukey method. The solid line in box locates the median sample. The hidden line indicates the average value. The circle indicates the outlier. Different lowercase letters indicate significant differences $(p<0.05)$ among the harvest dates.

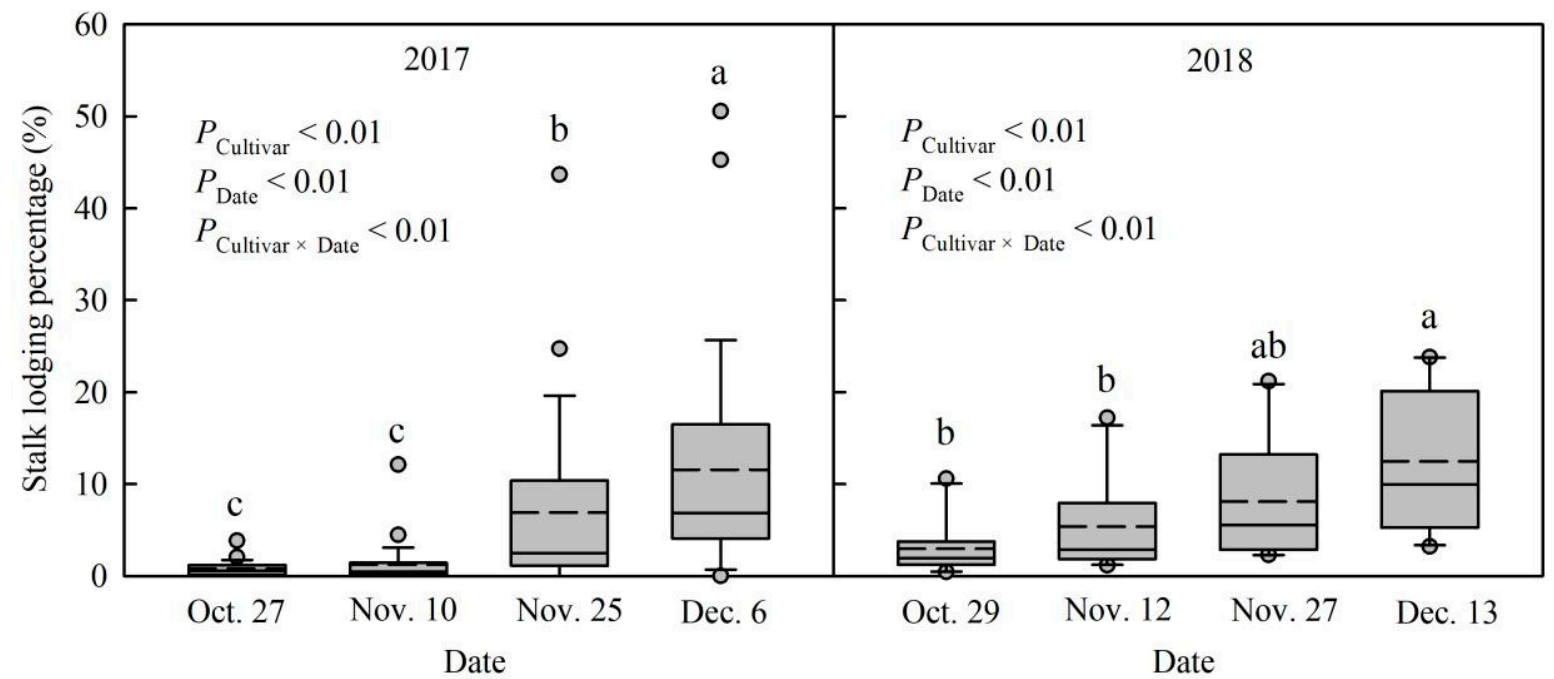

Figure 4. Natural stalk lodging rate of different maize cultivars after physiological maturity. The main box designates IQR containing 50\% samples in a Box-whisker Plot. The two sidelines indicate the reasonable sample border in Tukey method. The solid line in box locates the median sample. The hidden line indicates the average value. The circle indicates the outlier. Different lowercase letters indicate significant differences $(p<0.05)$ among the harvest dates.

The incidence of stalk rot was significantly positively correlated with stalk lodging rate under natural conditions (Figure 5). Based on the coefficient of determination $\left(R^{2}\right)$ of fitting equation, $24 \%$ of stalk lodging could be induced by stalk rot. Moreover, an increase of $0.14 \%$ of stalk lodging had been found with each $1 \%$ increase in stalk rot. This indicated that stalk rot is an important factor that affects the lodging of maize after PM.

\subsection{Infection Index and Stalk Inoculation}

The infection index gradually increased with days after PM (Figure 6). The infection index of same treatment was lower in 2017 than that in 2018. The infection index of Dika 517 was lower than that of Zhengdan 958 and Jingnongke 728. Stalk rot also occurred after $\mathrm{PM}$ in the treatment that was not inoculated. 


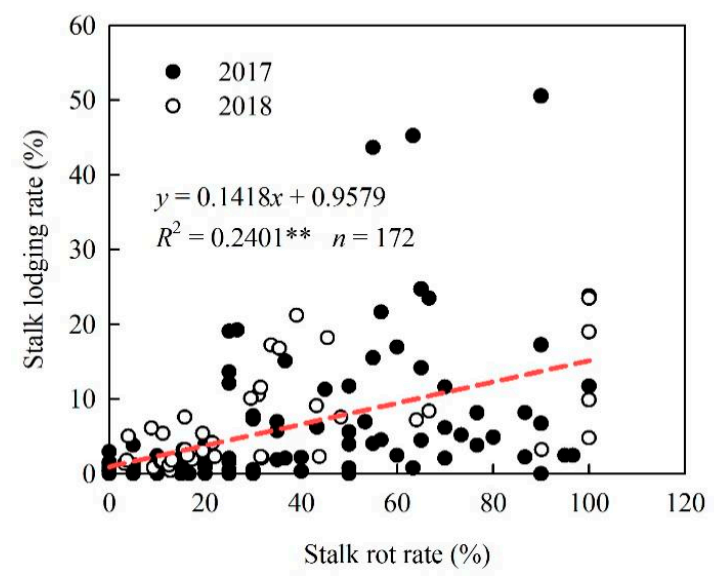

Figure 5. Relation between natural stalk rot and natural stalk lodging of different maize cultivars.

** indicates significance at $p<0.01$.

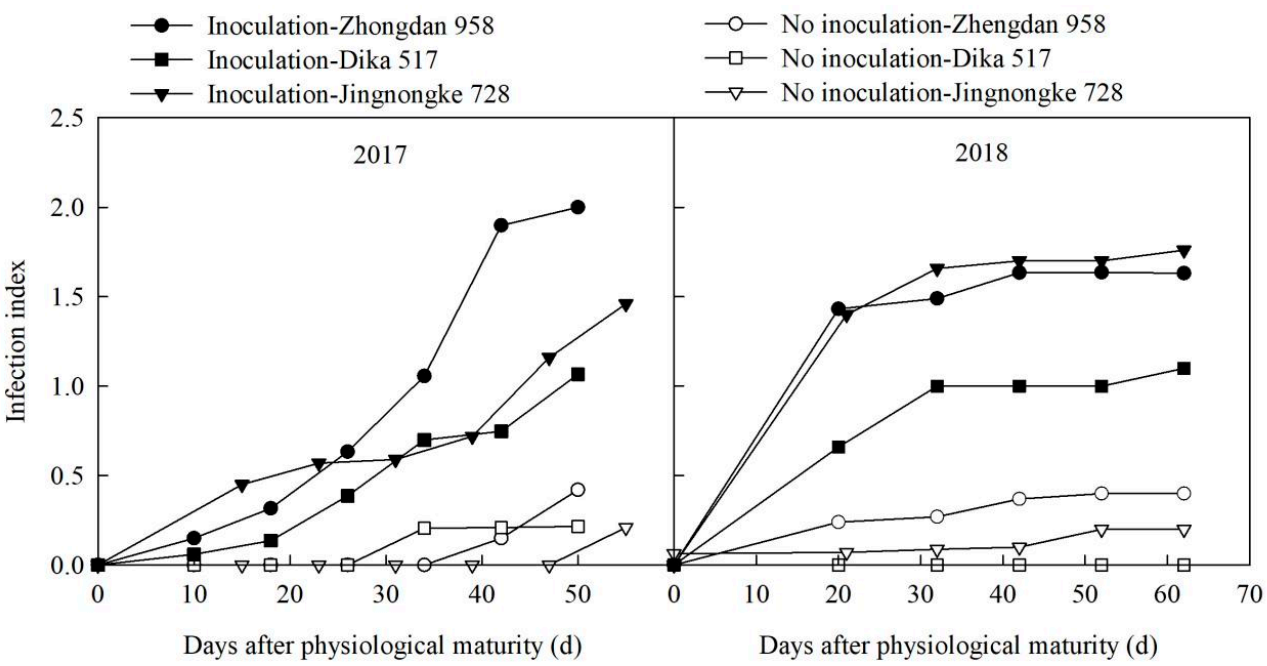

Figure 6. Infection index of different maize cultivars after physiological maturity under inoculation treatment.

Different parts of internode cross section were observed to determine the infection process of $P$. aristosporum. The infection gradually increased from the cortex to center of pith on the 20th day after inoculation (Figure 7). The infection gradually increased with days after inoculation. The vascular bundle of cortex gradually degraded from the 20th day to the 60th day after inoculation (Figure 8).
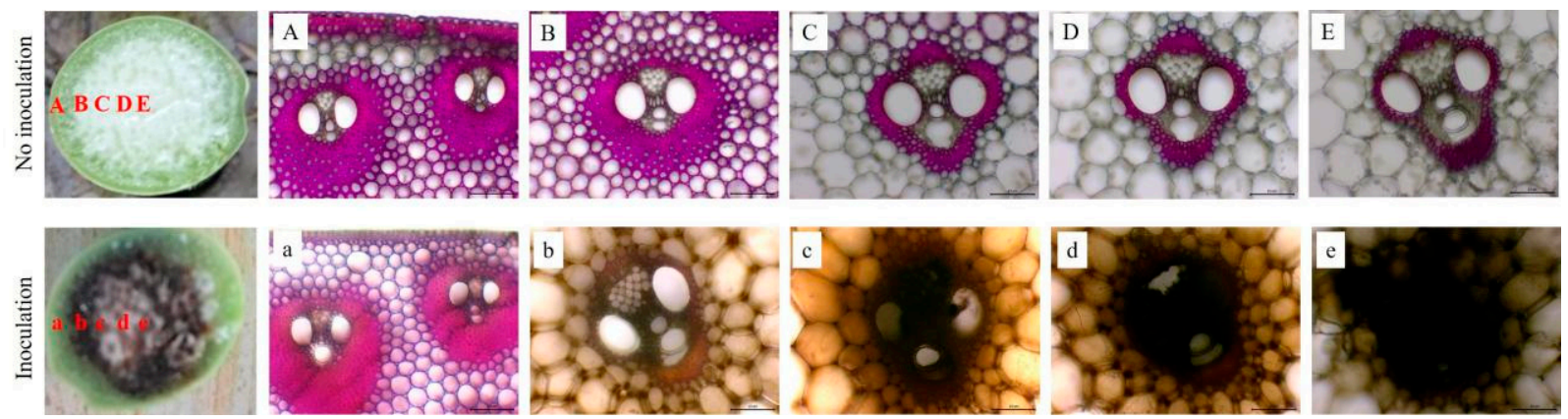

Figure 7. Infection of the vascular bundle in the internode cross section on the 20th day after the inoculation of Pythium aristosporum (Dika517, 2018). (A,a) indicate the cortex; (B,b) indicate a quarter of the cortex to center of pith; $(\mathbf{C}, \mathbf{c})$ indicate the half of cortex to center of pith; $(\mathbf{D}, \mathbf{d})$ indicate three quarters of the cortex to center of pith, and $(\mathbf{E}, \mathbf{e})$ indicate the center of pith. 

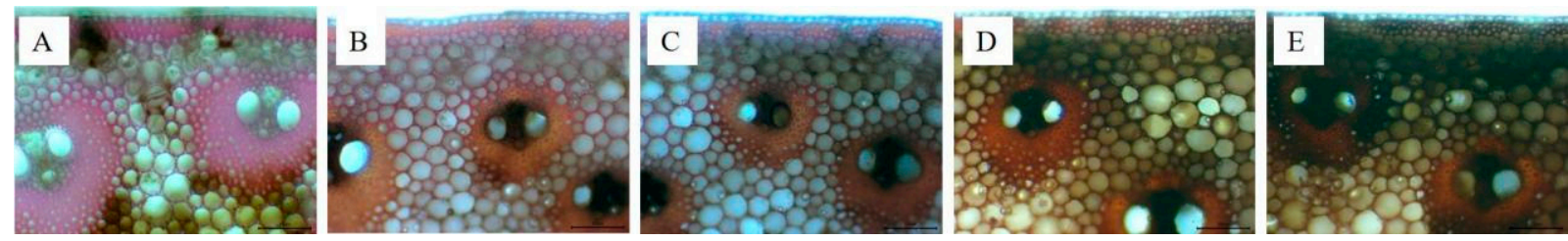

Figure 8. Infection the internode cortex after the inoculation of Pythium aristosporum (Dika517, 2018). (A-E) indicate the 20th day, 30th day, 40th day, 50th day, and the 60th day after inoculation, respectively.

\subsection{Crushing Strength (CS) after Stalk Inoculation}

CS of the basal internodes above soil gradually decreased with days after PM (Figure 9). In 2017, compared with the no-inoculation treatment, inoculation treatment significantly reduced the CS of the third internode for Zhengdan 958 by $12.5-56.7 \%$, for Dika 517 by $4.6-13.3 \%$, and for Jingnongke 728 by $15.8-30.6 \%$. In 2018 , inoculation treatment significantly reduced the CS for for Zhengdan 958 by $5.1-20.1 \%$, Dika 517 by $14.3-35.4 \%$, and for Jingnongke 728 by $16.1-31.9 \%$. In 2017, the reduction of CS after PM of Zhengdan 958 was higher than that of Dika 517 and Jingnongke 728. In 2018, the reduction of CS after PM of Dika517 was higher than that of Zhengdan 958 and Jingnongke 728. However, being Dika 517 , its CS was higher than that of the other two cultivars.
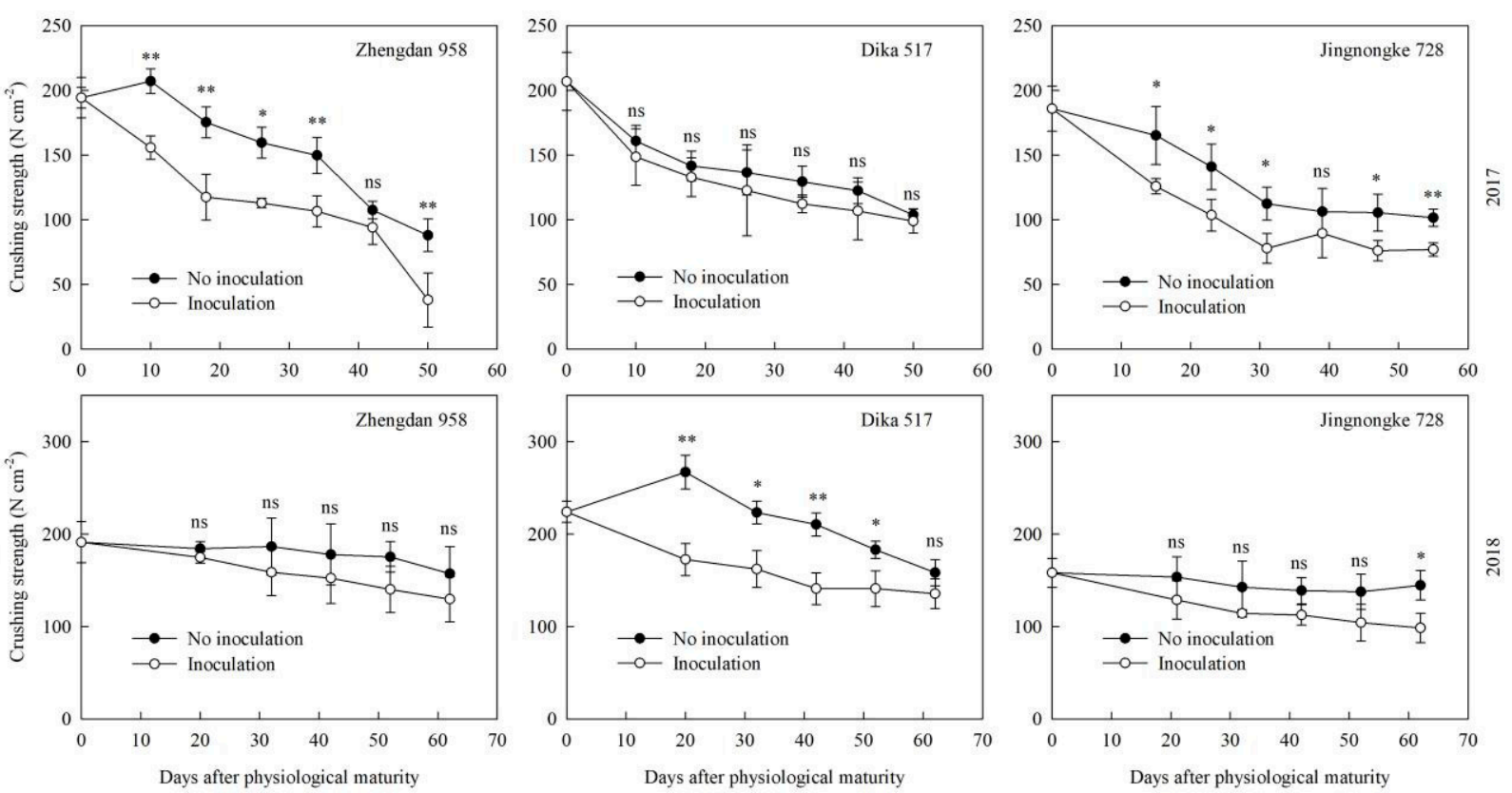

Figure 9. Internode crushing strength after physiological maturity of different maize cultivars with an inoculation of Pythium aristosporum. ${ }^{*}$ and ${ }^{* *}$ represent significant differences between inoculation and no inoculation at 0.05 and 0.01 levels, respectively, "ns" represent no significant difference.

\subsection{Accumulation of Carbohydrates after Stalk Inoculation}

Total soluble sugar firstly increased and then decreased with days after PM, while cellulose firstly decreased and then increased (Figure 10). Compared with the no-inoculation treatment, inoculation treatment decreased total soluble sugar content but increased cellulose. With days after PM, lignin gradually increased in inoculation treatment but gradually decreased in the no-inoculation treatment, and the lignin content after PM in inoculation 
treatment was higher than that of the no-inoculation treatment. Furthermore, the variation of hemicellulose was not consistent.

A correlation analysis showed that the CS was significantly positively correlated with the total soluble sugar content (Table 2), but significantly negatively correlated with the content of cellulose and lignin. There was no significant correlation between CS and the content of hemicellulose.

Table 2. Correlations among carbohydrates and the crushing strength of maize stalks.

\begin{tabular}{lcccc}
\hline & $\begin{array}{c}\text { Total Soluble } \\
\text { Sugar }\end{array}$ & Cellulose & Lignin & Hemicellulose \\
\hline Crushing strength & $0.519^{* *}$ & $-0.587^{* *}$ & $-0.481^{*}$ & $-0.134 \mathrm{~ns}$ \\
\hline${ }^{*}$ significant at $p<0.05 ;{ }^{* *}$ significant at $p<0.01 ;$ ns indicates a lack of significance. $(n=24)$. &
\end{tabular}
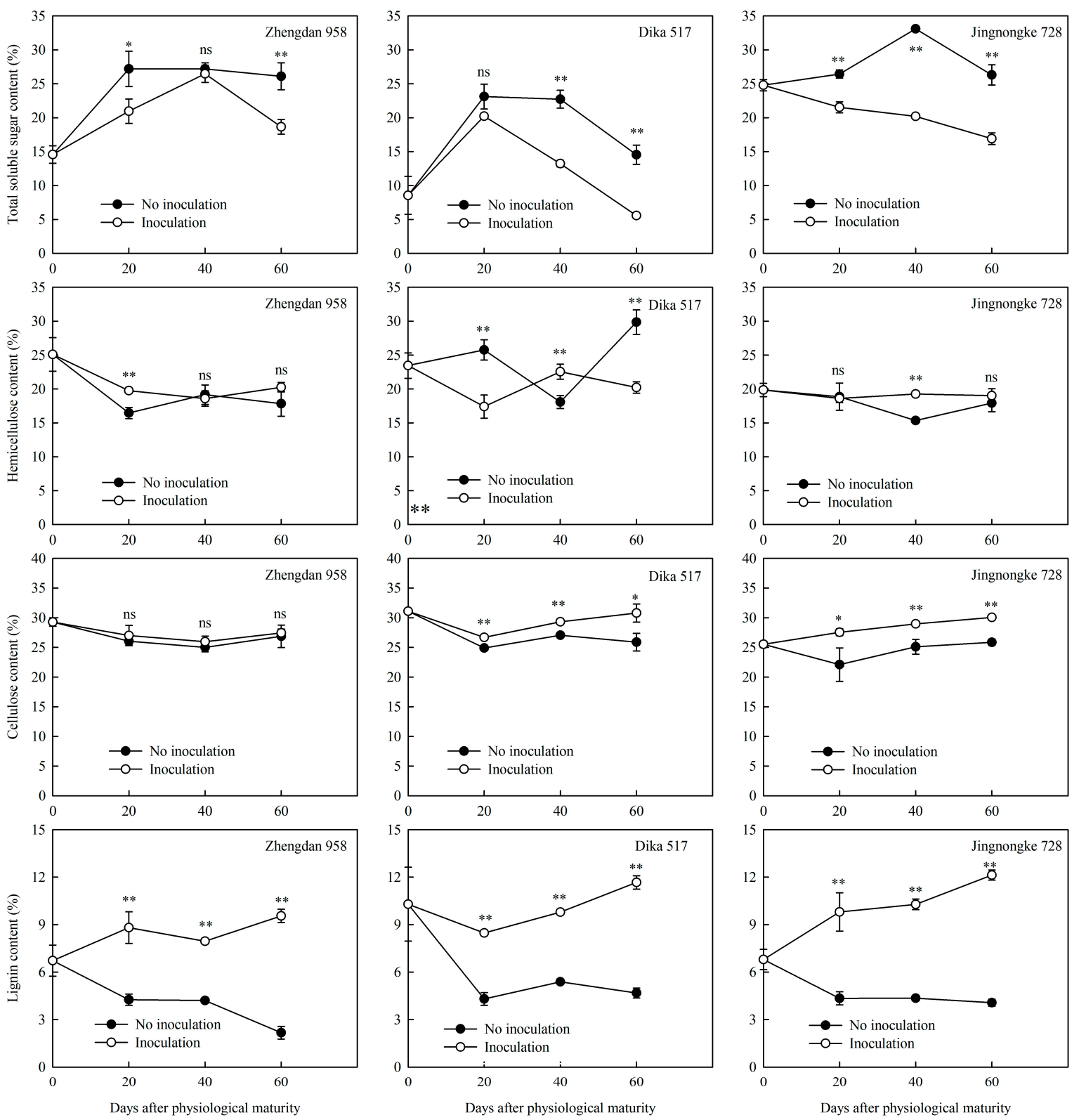

Figure 10. Internode carbohydrates after physiological maturity of different maize cultivars with an inoculation of Pythium aristosporum (2018). ${ }^{*}$ and ${ }^{* *}$ represent significant differences between inoculation and no inoculation treatments at 0.05 and 0.01 levels, respectively, "ns" represent no significant difference. 


\section{Discussion}

Previous researches on maize stalk rot were focused on the stage before physiological maturity $[13,14,29]$. In China, the transition of harvesting has put forward higher requirements for the prevention of stalk rot after PM. This study showed that the stalk rot and lodging gradually increased after PM of the 35 maize cultivars. In addition, the incidence of stalk rot was linearly positive-correlated with the stalk lodging after PM. Under natural condition, cultivars with different stalk rot resistance had different response to the risk of stalk lodging. However, stalk rot was only responsible for $24 \%$ of the stalk lodging variation. This indicates that the stalk rot after PM was an important factor that affects stalk lodging, but not the only one. Stalk lodging may also be related to other factors, such as genotype, plant density, rain and strong wind, and so on. Rainfall and high temperature were the key factors affecting stalk rot [21]. The rainfall of October in 2017 was higher than that in 2018. Therefore, the increase rate of stalk rot percentage for same cultivars was high in 2017.

In this study, the infection progress occurred from the pith to the rind in inoculation treatment, which can be explained by the high proportion of parenchymatous cells found in large vascular bundles in the pith, and the high proportion of sclerenchyma cells in the rind. The parenchymatous cells were more susceptible to infection and the sclerenchyma cells in the rind gradually degraded with days after PM. This process weakens the stalk tissue, thus reducing its mechanical strength, which fatefully leads to stalk lodging. The infection index reflected the longitudinal diffusion of pathogen, in longitudinal sections of the maize stalk tissues, the stalk rot pathogen spread from the inoculated internode upwardly and downwardly, eventually causing the adjacent internodes to rot. The infection progress varied among different maize cultivars; among them, the infection in Dika 517 was lower than that in Zhengdan 958 and Jingnongke 728.

The stalk rot pathogens require energy supply during the infection process. Because structural carbohydrates, such as cellulose and lignin in maize stalk, are not easily degraded [30], the content of soluble sugar is primarily used as energy during the infection process. This study showed that, compared with the no-inoculation treatment, the inoculation treatment reduced the percentage of soluble sugar but increased cellulose and lignin; hence, the percentage of soluble sugar was significantly positive-correlated with the CS of maize stalk. In addition, the resistance of maize plants to stalk rot is related to physiological activity and soluble sugar content of stalk, and previous studies showed that higher water and soluble sugar contents in maize make for a higher of resistance to stalk rot $[10,31,32]$. The enzymatic activities of phenylalanine ammonia lyase (PAL), peroxidase (POD), and polyphenol oxidase (PPO) are also significantly positive-correlated with resistance to stalk rot of maize [33,34]. Additionally, pith senescence in stalk could reduce the amount of sugar. Therefore, the reduction of stalk activity, moisture, and soluble sugar after PM could issue in declining of disease resistance that renders the plant susceptible to the infection of stalk rot. Simultaneously, after infection, the downtrend of soluble sugar content is accelerated by stalk rot pathogen. The process of plant senescence eventually leads to stalk strength reduction and an increasing risk of lodging after PM (Figure 11).

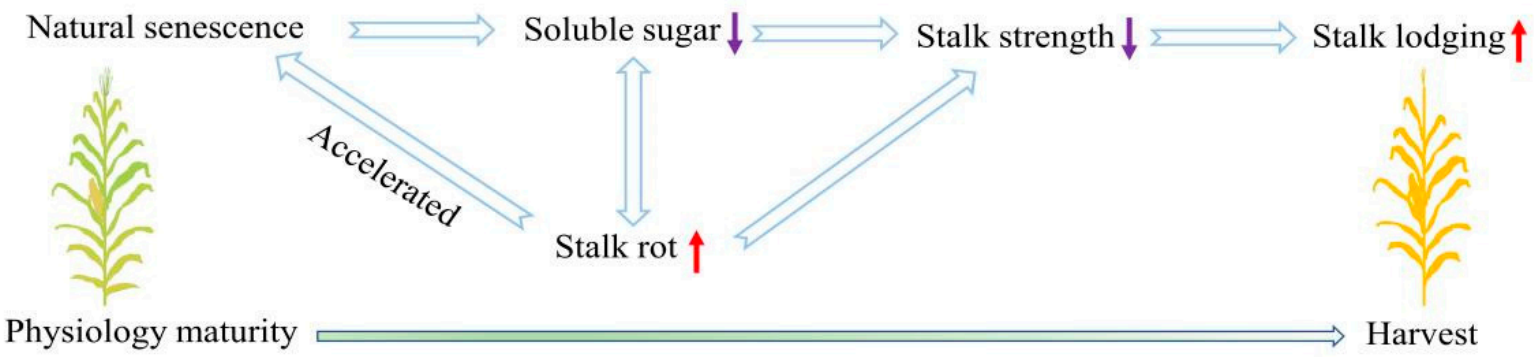

Figure 11. Effect of stalk rot on maize lodging after physiological maturity. 


\section{Conclusions}

The reduction of soluble sugar content during the natural senescence of maize stalk after physiological maturity (PM) was an important factor for the degradation of stalk strength, hereby aggravating stalk lodging. The incidence of stalk rot gives rise to the decomposition of soluble sugar, reducing stalk strength and greatly increasing the risk of stalk lodging. In maize production, breeders can manage to improve the resistance to stalk lodging by selecting and breeding cultivars with a high resistance to stalk rot and a vibrant stalk activity after PM, and the stalk strength before PM can be improved to prevent and control stalk rot infection with such cultivation practices as a proper planting density, growth regulation, and water and fertilizer management.

Author Contributions: Conceptualization, J.X. and S.L.; methodology, J.X. and S.L.; investigation, J.X., S.G. and L.L.; data analysis, J.X., R.X., K.W., B.M., P.H. and S.L.; writing-original draft preparation, J.X.; writing-review and editing, J.X., L.H., R.X., K.W., B.M., P.H. and S.L.; supervision, J.X. and S.L.; project administration, J.X. All authors have read and agreed to the published version of the manuscript.

Funding: This work was supported by National Key Research and Development Program of China, Grant number 2018YFD0100206, China Agriculture Research System of MOF and MARA, Agricultural Science and Technology Innovation Program (CAAS-ZDRW202004).

Institutional Review Board Statement: Not applicable.

Informed Consent Statement: Not applicable.

Data Availability Statement: Not applicable.

Acknowledgments: The authors are grateful to Zhihuan Yang (Institute of Crop Sciences, Chinese Academy of Agricultural Sciences) for her great help in the reproduction of P. aristosporum.

Conflicts of Interest: The authors declare no conflict of interest.

\section{References}

1. Li, S.K.; Zhao, J.R.; Dong, S.T.; Zhao, M.; Li, C.H.; Cui, Y.H.; Liu, Y.H.; Gao, J.L.; Xue, J.Q.; Wang, L.C. Advances and prospects of maize cultivation in China. Sci. Agric. Sin. 2017, 50, 1941-1959.

2. Chai, Z.W.; Wang, K.R.; Guo, Y.Q.; Xie, R.Z.; Li, L.L.; Hu, P.; Liu, C.W.; Chu, Z.D.; Zhang, W.X.; Zhang, G.Q.; et al. Currentstatus of maize mechanical grain harvesting and its relationship with grain moisture content. Sci. Agric. Sin. 2017, 50, $2036-2043$.

3. Li, L.; Ming, B.; Xie, R.; Wang, K.; Hou, P.; Gao, S.; Chu, Z.; Zhang, W.; Huang, Z.; Li, H.; et al. The stability and variability of maize kernel moisture content at physiological maturity. Crop Sci. 2021, 61, 704-714. [CrossRef]

4. Thomison, P.R.; Mullen, R.W.; Lipps, P.E.; Doerge, T.; Geyer, A.B. Corn response to harvest date as affected by plant population and hybrid. Agron. J. 2011, 103, 1765-1772. [CrossRef]

5. Li, L.L.; Xue, J.; Xie, R.Z.; Wang, K.R.; Ming, B.; Hou, P.; Gao, S.; Li, S.K. Effects of grain moisture content on mechanical grain harvesting quality of summer maize. Acta Agron. Sin. 2018, 44, 1747-1754. [CrossRef]

6. Nolte, B.H.; Byg, D.M.; Gill, W.E. Timely Field Operations for Corn and Soybeans in Ohio; The Ohio State University Cooperative Extension Service Bulletin 605: Reynoldsburg, OH, USA, 1976.

7. Xue, J.; Wang, Q.; Li, L.L.; Zhang, W.X.; Xie, R.Z.; Wang, K.R.; Ming, B.; Hou, P.; Li, S.K. Changes of maize lodging after physiological maturity and its influencing factors. Acta Agron. Sin. 2018, 44, 1782-1792. [CrossRef]

8. Xue, J.; Xie, R.Z.; Zhang, W.F.; Wang, K.R.; Hou, P.; Ming, B.; Gou, L.; LI, S.K. Research progress on reduced lodging of high-yield and-density maize. J. Integr. Agric. 2017, 16, 2717-2725. [CrossRef]

9. Martin, M.J.; Russell, W.A. Correlated responses of yield and other agronomic traits to recurrent selection for stalk quality in a maize synthetic. Crop Sci. 1984, 24, 746-750. [CrossRef]

10. Anderson, B.; White, D. Evaluation of methods for identification of corn genotypes with stalk rot and lodging resistance. Plant Dis. 1994, 78, 590-593. [CrossRef]

11. Li, W.; He, P.; Jin, J. Effect of potassium on ultrastructure of maize stalk pith and young root and their relation to stalk rot resistance. Agr. Sci. China 2010, 9, 1467-1474. [CrossRef]

12. Khokhar, M.K.; Hooda, K.S.; Sharma, S.S.; Singh, V. Post flowering stalk rot complex of maize-present status and future prospects. Maydica 2014, 59, 226-242.

13. Duan, C.X.; Wang, X.M.; Wu, X.F.; Yang, Z.H.; Song, F.J.; Zhao, L.P.; Sun, S.L.; Zhu, Z.D. Analysis of maize accessions resistance to pythium stalk rot and Fusarium ear rot. J. Plant Genet. Resour. 2015, 16, 948-955.

14. Wang, X.M.; Wu, Q.A.; Liu, X.J.; Ma, G.Z. Identification and pathogenicity of pythium spp. Isolated from maize. Acta Phytopathol. Sin. 1994, 24, 343-346. 
15. Pronczuk, M.; Pronczuk, S.; Messyasz, M. Pathogenicity of Fusarium spp. contributing to the stalk rot of maize in Poland. Mycotoxin Res. 1991, 7, 97-101. [CrossRef]

16. Quesada-Ocampo, L.M.; Al-Haddad, J.; Scruggs, A.C.; Buell, C.R.; Trail, F. Susceptibility of maize to stalk rot caused by Fusarium graminearum deoxynivalenol and zearalenone mutants. Phytopathology 2016, 106, 920-927. [CrossRef]

17. Yu, C.; Saravanakumar, K.; Xia, H.; Gao, J.; Fu, K.; Sun, J.; Dou, K.; Chen, J. Occurrence and virulence of Fusarium spp. associated with stalk rot of maize in North-East China. Physiol. Mol. Plant Pathol. 2017, 98, 1-8. [CrossRef]

18. Hao, J.J.; Xie, S.N.; Sun, J.; Yang, G.Q.; Liu, J.Z.; Xu, F.; Ru, Y.Y.; Song, Y.L. Analysis of Fusarium graminearum species complex from wheat-maize rotation regions in Henan (China). Plant Dis. 2017, 101, 720-725. [CrossRef]

19. Qin, Z.H.; Ren, X.; Jiang, K.; Wu, X.F.; Yang, Z.H.; Wang, X.M. Identification of Fusarium species and F. graminearum species complex causing maize ear rot in China. Acta Phytophy Sin. 2014, 41, 589-596.

20. Liu, S.; Ma, H.; Guo, N.; Shi, J.; Zhang, H.; Sun, H.; Jin, G. Analysis of main pathogens and dominant species of maize stalk rot in the main summer maize producing areas of Huang-Huai-Hai. Sci. Agric. Sin. 2019, 52, 262-272.

21. Chen, J.; Song, Z.H.; Xian, H.Q.; Wang, C.R. Infection pattern of corn stalk rot caused by Fusarium and Pythium. Acta Phytophy Sin. 1995, 22, 117-122.

22. Lipps, P.; Dorrance, A.; Mills, D. Corn Disease Management in Ohio, Bulletin 804; The Ohio State University: Columbus, OH, USA, $2004 ;$ p. 802.

23. Novacek, M.; Mason, S.; Galusha, T.; Yaseen, M. Twin rows minimally impact irrigated maize yield, morphology, and lodging. Agron. J. 2013, 105, 268-276. [CrossRef]

24. Xue, J.; Gao, S.; Fan, Y.; Li, L.; Ming, B.; Wang, K.; Xie, R.; Hou, P.; Li, S. Traits of plant morphology, stalk mechanical strength, and biomass accumulation in the selection of lodging-resistant maize cultivars. Eur. J. Agron. 2020, 117, 126073. [CrossRef]

25. Yoshida, S.; Forno, D.A.; Cock, J.H. Fundamentals of Rice Crop Science; International Rice Research Institute: Los Baños, Philippines, 1971.

26. Li, H.S. Principles and Techniques of Plant Physiological Experiment; Higher Education Press: Beijing, China, 2000.

27. Van Soest, P.J.; Robertson, J.B.; Lewis, B.A. Methods for dietary fiber, neutral detergent fiber, and nonstarch polysaccharides in relation to animal nutrition. J. Dairy Sci. 1991, 74, 3583-3597. [CrossRef]

28. Zhou, D.; Chen, J.; She, J.; Tong, J.; Chen, Y. Temporal dynamics of shearing force of rice stem. Biomass Bioenergy 2012, 47, 107-114. [CrossRef]

29. Guo, C.; Wang, B.B.; Yang, Y.; Wang, C.M.; Zhou, T.W.; Li, M.Q.; Duan, X.C. Advances in studies of maize stalk rot. J. Plant Genet. Resour. 2019, 20, 1118-1128.

30. Xue, J.; Zhao, Y.; Gou, L.; Shi, Z.; Yao, M.; Zhang, W. How high plant density of maize affects basal internode development and strength formation. Crop Sci. 2016, 56, 3295-3306. [CrossRef]

31. Craig, J.; Hooker, A.L. Relation of sugar trends and pith density to diplodia stalk rot in dent corn. Phytopathology 1961, 51, 376-382.

32. Albrecht, K.; Martin, M.; Russel, W.; Wedin, W.; Buxton, D. Chemical and in vitro digestible dry matter composition of maize stalks after selection for stalk strength and stalk-rot resistance. Crop Sci. 1986, 26, 1051-1055. [CrossRef]

33. Li, Y.L.; Long, S.S.; Guo, J.Z.; Zhang, Y.H.; Li, Q.; Wang, W. Changes of activities of PAL and POD and bands of POD isozyme of susceptible and resistant corn infected with Fusarium graminearum. Acta Bot. Boreal.-Occident. Sin. 2003, 23, $1927-1931$.

34. Mohammadi, M.; Kzami, H. Changes in peroxidase and polyphenol oxidase activities in susceptible and resistant wheat heads inoculated with Fusarium graminearum and induced resistance. Plant Sci. 2002, 162, 491-498. [CrossRef] 